\title{
Effects of a high-fat diet on superoxide anion generation and membrane fluidity in liver mitochondria in rats
}

\author{
M Togo ${ }^{1 *}$, N Konari ${ }^{2}$, M Tsukamoto ${ }^{3}$, R Kimoto ${ }^{4}$, T Yamaguchi ${ }^{1}$, H Takeda $^{5}$ and I Kambayashi ${ }^{6}$
}

\begin{abstract}
Background: Obesity is a primary factor of lifestyle-related diseases, and the age of its onset has decreased. The reactive oxygen species (ROS), the superoxide anion, is generated in the mitochondrial electron transport chain and the damage it induces in cells may be a contributing factor to obesity-related lifestyle diseases. In the present study, the influence of the ingestion of a high-fat diet (HFD) on superoxide anion generation in rat liver mitochondria (Mt) and membrane fluidity was investigated.

Methods: Male Wistar rats were fed a normal diet $(N D, n=6)$ or HFD $(n=6)$. Liver Mt were isolated and oxygen consumption, superoxide anion production (the adrenaline method), and membrane fluidity (the spin label method) were measured.

Results: After 11 weeks, body weights and abdominal circumferences were higher in the HFD group than in the ND group. Mt oxygen consumption was higher in the HFD group than in the ND group. Superoxide anion production was significantly lower in the HFD group than in the ND group, while no significant changes were observed in membrane fluidity.

Conclusion: Although rats developed diet-induced obesity, it did not reach the level of disease development. The promotion of lipid metabolism appeared to reduce superoxide anion production, but did not influence membrane fluidity. While superoxide anion damages cells as an oxidative stress, ROS and superoxide dismutase are essential signaling molecules in the body. The present results suggest that the continuous ingestion of a HFD impairs Mt and induces disease development.
\end{abstract}

Keywords: High-fat diet, Liver mitochondria, Superoxide anion, Adrenaline method, Membrane fluidity, Spin labels

\section{Background}

Obesity is a growing health issue worldwide and the age of its onset has been decreasing. Since obesity progresses to diabetes, hypertension, and dyslipidemia [1], its treatment is important for the prevention of disease development. Diseases develop from obesity through a number of mechanisms, including oxidative stress induced by reactive oxygen species (ROS) [2].

An obesity-induced increase in leptin levels in the body has been shown to promote inflammatory reactions [3].

\footnotetext{
* Correspondence: s21534101@stu.rakuno.ac.jp

1 Graduate School of Dairy Sciences, Rakuno Gakuen University, 582,

Midorimachi Bunkyodai, Ebetsu, Hokkaido 069-8501, Japan

Full list of author information is available at the end of the article
}

These inflammatory reactions increase TNF- $\alpha$ and IL-6 levels, which, in turn, activate NADPH oxidase and induce the extravascular migration of immune cells, thereby increasing ROS production and oxidizing lipids and proteins [4]. An increase in oxidative stress marker levels has been reported in obese individuals [5]. The urinary level of 8-epiPGF2 $\alpha$, which is a lipid oxidative stress marker, has been correlated with obesity and becomes elevated with increases in BMI [6]. In rats fed a high-fat diet (HFD) that increased body weight, an increase in oxidative stress marker levels was detected in the liver [7] and skeletal muscle [8].

ROS are essential for normal physiological functions, gene expression, cell growth, defense against infections, and the control of vascular endothelial cells [9-11]. 
However, when ROS production exceeds scavenging abilities, cells are exposed to oxidative stress and are damaged [2]. Mitochondria (Mt), which consume approximately $90 \%$ of intracellular oxygen [12], constantly produce a specific amount of the superoxide anion $\left(\mathrm{O}_{2}^{-}\right)$ in the electron transport chain in the inner membrane $[13,14]$. A previous study reported that hydrogen peroxide production was increased in skeletal muscle $\mathrm{Mt}$ in obese rats [8]. Therefore, the influence of obesity on $\mathrm{O}_{2}^{-}$ production in $\mathrm{Mt}$ and the importance of evaluating inflammatory progression-induced ROS production need to be clarified; however, only a few studies have been conducted, and $\mathrm{O}_{2}^{-}$production as an index has not yet been investigated. Another area that warrants further study is the impact of membrane fluidity and $\mathrm{O}_{2}^{-}$production in relation to the lipid composition of a diet. The electron transport chain is present in the inner membrane of $\mathrm{Mt}$, and membrane fluidity influences electron leakage in the inner membrane, which alters the production of $\mathrm{O}_{2}^{-}$. The Mt membrane is affected by the amount and components of ingested lipids and, thus, membrane fluidity is altered [15-17].

The present study had the following objectives: 1) to quantitate and evaluate $\mathrm{Mt} \mathrm{O}_{2}^{-}$production in the livers of rats with HFD-induced obesity, and 2) to clarify the relationship between $\mathrm{Mt}$ membrane fluidity and $\mathrm{O}_{2}^{-}$ production.

\section{Methods}

\section{Experimental animals}

Twelve male Wistar rats were used as experimental animals in the present study. Animals were maintained at a room temperature of $24 \pm 2^{\circ} \mathrm{C}$ and humidity of $50 \pm 5 \%$ under a lighting cycle (lights on: 7:00-19:00, lights off 20:00-6:00). They were housed in plastic cages at 2-3 animals/cage (width: $206 \mathrm{~mm}$, depth: $365 \mathrm{~mm}$, height: $197 \mathrm{~mm}$ ), and given free access to food and drinking water. Animals only moved inside the cage throughout the maintenance period.

\section{Feed}

Rats were given a normal diet (ND) or HFD. MF pellets (Oriental Yeast Co., Ltd.) were used for the ND, and $58 \mathrm{Y} 1$ with a lard content of $60 \%$ (PMI) was used for the HFD. The nutritive values (PFC ratio) of the ND were: $360 \mathrm{kcal} / 100 \mathrm{~g}$; protein, $23.6 \mathrm{~g}$ (26.2\%); lipids, $5.3 \mathrm{~g}$ (13.3\%); and carbohydrates, $54.4 \mathrm{~g}(60.5 \%)$; and those of the HFD were: $510 \mathrm{kcal} / 100 \mathrm{~g}$; protein, $23.6 \mathrm{~g}$ (18.3\%); lipids, $34.9 \mathrm{~g}$ (60.9\%); and carbohydrates, $25.9 \mathrm{~g}$ (20.8\%). The fatty acid composition of the HFD was $41.2 \%$ saturated fatty acids and $58.8 \%$ unsaturated fatty acids (from mono- and polyunsaturated fatty acids, the latter of which includes phospholipid components, such as linoleic acid, linolenic acid, and arachidonic acid).

\section{Outline of the experiment}

Rats were acclimated for one week from 3 weeks old and divided into the ND $(n=6)$ and HFD $(n=6)$ groups. They ingested the test diets for 11 weeks. Body weights and abdominal circumferences were measured, blood was collected from the heart, and the liver was excised at 15 weeks old. After the extraction of Mt, respiratory activity and substrate oxygen consumption in the liver were analyzed. Regarding Mt, sub-mitochondrial particles (SMP) were prepared to isolate the electron transport chain, and $\mathrm{O}_{2}^{-}$production was measured. Mt and SMP were subjected to membrane fluidity measurements. Samples were stored at $-80^{\circ} \mathrm{C}$ until analyzed.

\section{Blood chemistry}

The blood chemistry items examined were total cholesterol (T-ch), triglycerides (TG), HDL cholesterol (HDL), LDL cholesterol (LDL), free fatty acids (FFA), glycated hemoglobin A1c (HbA1c), and glycoalbumin (GA). The augmentation index (AI) was calculated using the formula: (T-ch - HDL)/HDL [18-20].

\section{Extraction of liver Mt}

Mt were extracted as follows [21]: The liver was homogenized and centrifuged at $600 \times g$ for $10 \mathrm{~min}$. The supernatant was then centrifuged twice at $8000 \times g$ for $10 \mathrm{~min}$ and precipitated Mt were collected. The Mt protein level was adjusted to $15-30 \mathrm{mg} / \mathrm{mL}$ using the Bradford method [22].

\section{Measurement of Mt respiratory activity and substrate oxygen consumption}

Mt respiratory activity was measured using Clark's oxygen electrode (the liquid-phase oxygen monitoring system Oxygraph, Hansatech Instruments). Mt were subjected to measurements of the respiratory control ratio ( $\mathrm{RCR}$ ), $\mathrm{ADP} /$ oxygen ratio ( $\mathrm{P} / \mathrm{O}$ ratio), and oxygen consumption with succinic acid as a substrate.

RCR was measured as follows [23-26]: After confirming endogenous respiration (state 1) by incubating $50 \mu \mathrm{L}$ of $\mathrm{Mt}$ in $875 \mu \mathrm{L}$ of buffer $(0.25 \mathrm{M}$ sucrose, $0.1 \mathrm{M}$ HEPES, $0.1 \mathrm{M}$ EDTA, $20 \mathrm{mM} \mathrm{KCl}, 2 \mathrm{mM} \mathrm{MgCl}_{2}$, and $3 \mathrm{mM} \mathrm{KHPO}, \mathrm{pH} 7.4)$ at $25^{\circ} \mathrm{C}, 30 \mu \mathrm{L}$ of glutamic acid $(15 \mathrm{mM})$ and $30 \mu \mathrm{L}$ of malic acid $(15 \mathrm{mM})$ were added, and phosphorylation with the addition of $5 \mu \mathrm{L}$ of ADP $(0.5 \mu \mathrm{M})$ (state 3$)$ and ATP synthesis (state 4$)$ were then measured. RCR was calculated from oxygen consumption in states 3 and 4 using the formula: state 3/state 4 (Fig. 1) [27]. The P/O ratio reflects the ATP-synthesizing activity of Mt, and was calculated using the following formula: Amount of ADP added/oxygen consumption in the presence of ADP (Fig. 1) [28].

Substrate oxygen consumption was measured as follows: After incubating $50 \mu \mathrm{L}$ of Mt in $930 \mu \mathrm{L}$ of buffer 


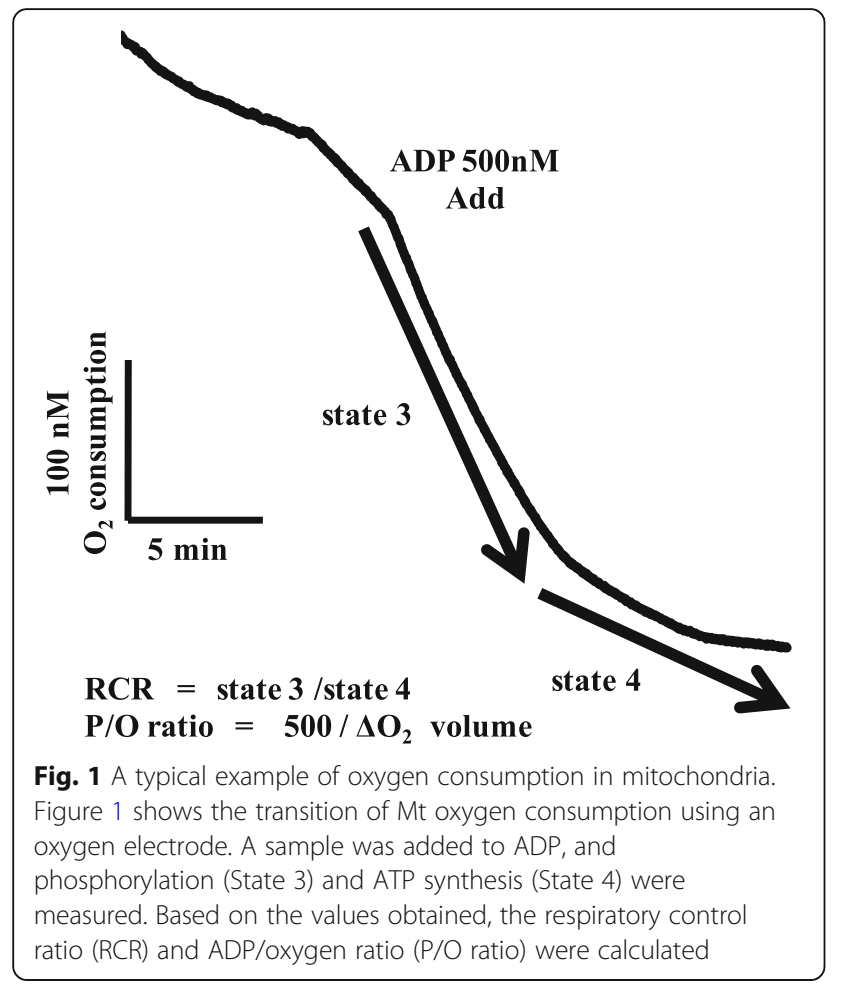

(0.25 M sucrose, 0.1 M HEPES, 0.1 M EDTA, $20 \mathrm{mM}$ $\mathrm{KCl}$, and $2 \mathrm{mM} \mathrm{MgCl}_{2}, \mathrm{pH} 7.4$ ) at $25^{\circ} \mathrm{C}, 10 \mu \mathrm{L}$ of succinic acid $(5 \mathrm{mM})$ was added, and after confirming substrate oxygen consumption, $10 \mu \mathrm{L}$ of antimycin $\mathrm{A}$ $(1 \mu \mathrm{M})$, which is a specific inhibitor of the electron transport chain, was added to stop substrate oxygen consumption. The respiratory activity and substrate oxygen consumption of Mt were calculated with corrections of the maximum slope with the protein level.

\section{Preparation of SMP}

SMP were prepared as follows [29, 30]: Mt were sonicated (Bioruptor, Cosmo Bio Co., Ltd.) followed by ultrasonication at Level 5, high, interval ON, $1.0 \mathrm{~s}$; OFF, $0.5 \mathrm{~s}$ (75 $\mathrm{s}$ in total). The sonicated sample was subjected to ultracentrifugation at $27,000 \times g$ for $10 \mathrm{~min}$, the supernatant was centrifuged 3 times at $77,000 \times g$ for $60 \mathrm{~min}$, and precipitated SMP (10-20 $\mathrm{mg} / \mathrm{mL})$ were subjected to analyses.

\section{Measurement of $\mathrm{O} \cdot \overline{2}$}

$\mathrm{O}_{2}^{-}$production by SMP was measured using the slightly modified adrenaline method $[29,30]$ and a dualwavelength recording spectrophotometer. The measurement conditions were set at a wavelength of 485-575 nm and $37^{\circ} \mathrm{C}$. After the incubation of $25 \mu \mathrm{L}$ of SMP combined with $900 \mu \mathrm{L}$ of buffer (0.25 M sucrose, 0.1 M HEPES, and $0.1 \mathrm{M}$ EDTA, pH 7.4), $15 \mu \mathrm{L}$ of succinic acid (7.5 mM), $10 \mu \mathrm{L}$ of antimycin $\mathrm{A}(1 \mu \mathrm{M}), 10 \mu \mathrm{L}$ of rotenone $(1 \mu \mathrm{M})$, and $10 \mu \mathrm{L}$ of adrenaline $(1 \mathrm{mM})$ for $5 \mathrm{~min}, 30 \mu \mathrm{L}$ of NADH $(0.9 \mathrm{mM})$ were added, and absorbance was measured to assess the amount of $\mathrm{O}_{2}^{-}$produced. It was calculated using the following formula: Adrenochrome production (min)/ millimolar extinction coefficient $\left(2.96 \mathrm{mM}^{-1} \cdot \mathrm{cm}^{-1}\right) \times$ protein content in the sample $(\mathrm{mg})$. The measured value was corrected by subtracting the value measured in the presence of the $\mathrm{O}_{2}^{-}$-scavenging enzyme superoxide dismutase (SOD; 1070 units).

\section{Analysis of membrane fluidity}

Mt membrane fluidity was measured using the spin label method [31] and an electron spin resonance device (Electron Spin Resonance, JEOL Ltd.). Using 5-nitroxyl stearate (5-NS, Fig. 2A) as the labeling agent, membrane fluidity was measured based on the binding of the nitroxide group to the alkyl chain of the phospholipid head on the external surface of the membrane. The sample was SMP, namely, the inner membrane of Mt prepared by isolating the outer membrane of $\mathrm{Mt}$ and the electron transport chain. In order to measure membrane fluidity, $0.6 \mu \mathrm{g}$ of 5-NS was vaporized with nitrogen gas in a glass tube, combined with $300 \mu \mathrm{L}$ of $\mathrm{Mt}(4 \mathrm{mg} / \mathrm{mL})$, and then mixed

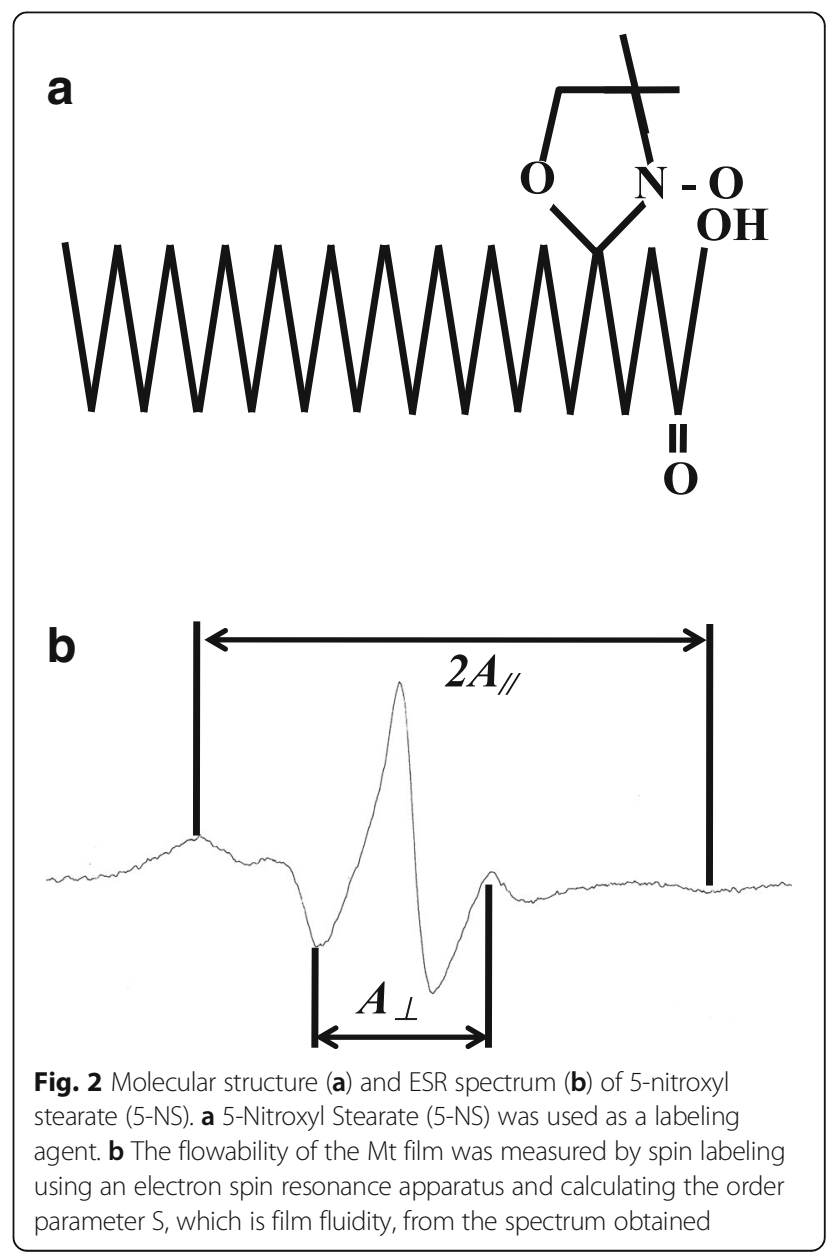


for $30 \mathrm{~min}$. After mixing, the sample was centrifuged at $8000 \times g$ for $10 \mathrm{~min}$ and the precipitate was subjected to measurements using ESR. ESR measurement conditions were: Sweep width, $\pm 5.0 \mathrm{mT}$; sweep time, $3.5 \mathrm{~min}$; gain, 5.0 or $6.3 \times 100$; modulation width, $2.0 \times 0.1 \mathrm{mT}$; time constant, $0.3 \mathrm{~s}$; center field, $337 \mathrm{mT}$; power, $6 \mathrm{~mW}$; frequency, 9.2 GHz; and the spectrum was measured (Fig. 2B). Based on the measured spectrum, the order parameter representing membrane fluidity, $\mathrm{S}$ (refer to the formula below $\left[A_{/ /,} A_{\perp}\right.$ : distance of the ESR spectrum of the spin label, $A_{z z}, A_{x x}, A_{y y}: \mathrm{x}-, \mathrm{y}-$, and z-axes of the principal axis of tensor]), was calculated and the principal axis of tensor was set at the principal value of 5-NS: $A_{z z}=6.3$, $A_{x x}=5.8, A_{y y}=33.6$ (Fig. 2B). Fluidity decreases as the order parameter, $\mathrm{S}$, becomes closer to 1 , and increases as $\mathrm{S}$ becomes closer to 0 .

$$
S=A_{/ /}-A_{\perp} / A_{z z}-1 / 2\left(A_{x x}+A_{y y}\right)
$$

\section{Statistical analysis}

Results are presented as the mean \pm standard error (mean \pm SE). Changes in body weight were subjected to a two-way layout analysis of variance with 2 factors: the dietary condition and time-course changes, and the dietary condition was compared using the unpaired Student's $t$-test, setting the significance level at $5 \%$.

\section{Results}

\section{Body composition and food intake}

Regarding changes in body weight during the dietary period between 3 and 15 weeks old (Fig. 3), body weight was significantly higher from week 8 in the HFD group than in the ND group $(p<0.05)$, and body weights were $412.7 \pm 13.2$ and $339.5 \pm 5.3 \mathrm{~g}$, respectively, at the time of autopsy. Regarding body composition at 15 weeks old (Table 1), the liver wet weight was not significantly different between the dietary conditions examined. Abdominal circumference was significantly higher in the HFD group than in the ND group $(p<0.01)$, and the liver/ body weight ratio was higher in the ND group than in the HFD group $(\mathrm{p}<0.01)$.

Mean daily food intakes per rat at 15 weeks old were 14.2 and $16.4 \mathrm{~g}$ in the HFD and ND groups, respectively, and energy intakes were 73.1 and $59.2 \mathrm{kcal}$, respectively.

\section{Blood chemistry}

The results of blood chemistry examinations (Table 2) showed no significant differences in T-ch, HDL, LDL, TG, FFA, HbA1c, or GA between the 2 dietary groups, whereas AI was significantly higher in the HFD group than in the ND group $(p<0.05)$.

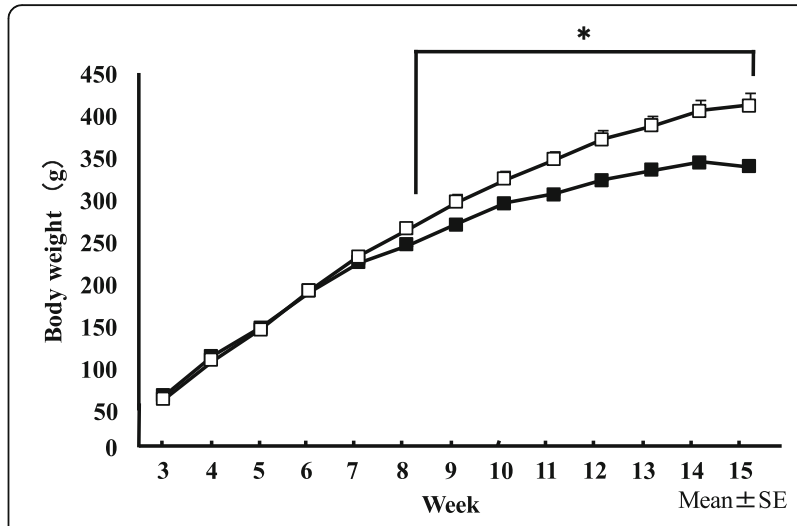

Fig. 3 Changes in body weight in ND (-) and HFD ( $\square$ ) groups. We conducted a two-way ANOVA of dietary conditions and time-course variance to change body weight and set the significance level to $5 \%$. Body weight gain was significantly higher in the HFD group than in the ND group from the 8th week. Error bars represent the standard deviation

\section{Mt respiratory activity and substrate oxygen consumption}

$\mathrm{RCR}$ and the $\mathrm{P} / \mathrm{O}$ ratio representing Mt respiratory activity and substrate oxygen consumption with succinic acid were compared in Fig. 4. RCR were $9.55 \pm 1.00$ and 10.31 \pm 1.83 in the HFD and ND groups, respectively, and were not significantly different. $\mathrm{P} / \mathrm{O}$ ratios were $3.48 \pm 0.25$ and $2.84 \pm 0.16$ in the HFD and ND groups, respectively, and was significantly in the HFD group $(p<0.05)$. Substrate oxygen consumption in the HFD and ND groups were $35.35 \pm 3.58$ and $24.83 \pm 1.82 \mathrm{nM} / \mathrm{min} / \mathrm{mg}$, respectively, and was significantly higher in the HFD group $(p<0.05)$.

\section{$0 . \overline{2}$ production}

$\mathrm{O}_{2}^{-}$production by SMP (Fig. 5) was $14.12 \pm 1.32 \mathrm{nM} /$ $\mathrm{min} / \mathrm{mg}$ in the ND group and $11.19 \pm 0.89 \mathrm{nM} / \mathrm{min} / \mathrm{mg}$ in the HFD group, and was significantly lower in the HFD group $(p<0.05)$.

\section{Membrane fluidity}

When the fluidities of the outer and inner membranes of Mt were measured (Fig. 6), values for the outer membrane were $0.653 \pm 0.003$ in the ND group and $0.652 \pm$ 0.003 in the HFD group, while those for the inner membrane were $0.636 \pm 0.005$ and $0.633 \pm 0.007$, respectively,

Table 1 Physical characteristics of ND and HFD groups

\begin{tabular}{lll}
\hline & ND & HFD \\
\hline Abdominal circumference $(\mathrm{cm})$ & $18.8 \pm 0.3$ & $21.7 \pm 0.3^{*}$ \\
Liver wet weight (g) & $9.8 \pm 0.2$ & $10.2 \pm 0.4$ \\
Liver/Weight ratio & $2.89 \pm 0.03^{*}$ & $2.47 \pm 0.06$ \\
\hline
\end{tabular}

Mean \pm SE

Values are after the consumption of each diet for 11 weeks measured at dissection $(n=6)$. The HFD group had a higher abdominal circumference than the ND group, with a lower liver/body weight ratio $\left({ }^{*} p<0.05\right)$ 
Table 2 Blood profile of ND and HFD groups

\begin{tabular}{lll}
\hline & ND & HFD \\
\hline Total cholesterol $(\mathrm{mg} / \mathrm{dl})$ & $55.8 \pm 5.9$ & $66.2 \pm 4.9$ \\
HDL cholesterol $(\mathrm{mg} / \mathrm{dl})$ & $25.8 \pm 1.4$ & $24.0 \pm 0.9$ \\
LDL cholesterol $(\mathrm{mg} / \mathrm{dl})$ & $7.0 \pm 2.9$ & $14.7 \pm 6.3$ \\
Triglyceride $(\mathrm{mg} / \mathrm{dl})$ & $104.0 \pm 12.6$ & $85.8 \pm 9.5$ \\
Free fatty acid $(\mathrm{mEq} / \mathrm{l})$ & $1.1 \pm 0.1$ & $1.0 \pm 0.1$ \\
Glycated hemoglobin A1c (\%) & $3.7 \pm 0.1$ & $3.7 \pm 0.1$ \\
Glycoalbmin(\%) & $3.8 \pm 0.2$ & $3.8 \pm 0.1$ \\
Augmentation index & $1.1 \pm 0.1$ & $1.8 \pm 0.2^{*}$ \\
\hline
\end{tabular}

Mean \pm SE

Values are blood test results after ingesting each diet for 11 weeks $(n=6)$ Although the HFD group showed no significant changes in carbohydrate and lipid test items from the ND group, the arterial stiffness index was high $\left({ }^{*} p<0.05\right)$

and were not significantly different between the two dietary conditions.

\section{Discussion}

The present study investigated the influence of dietinduced obesity on liver $\mathrm{Mt} \mathrm{O}_{2}^{-}$production and membrane fluidity in rats that had consumed HFD for 11 weeks. Energy metabolism was higher and $\mathrm{O}_{2}^{-}$production was lower

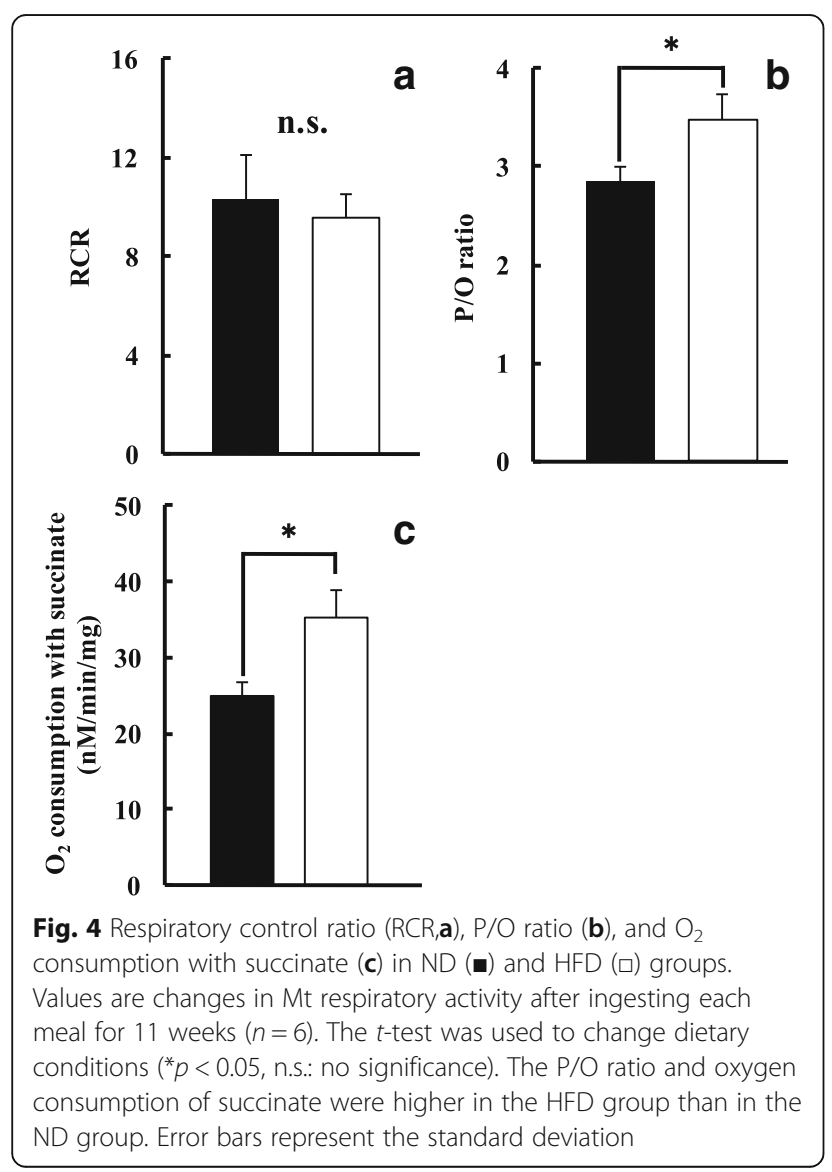

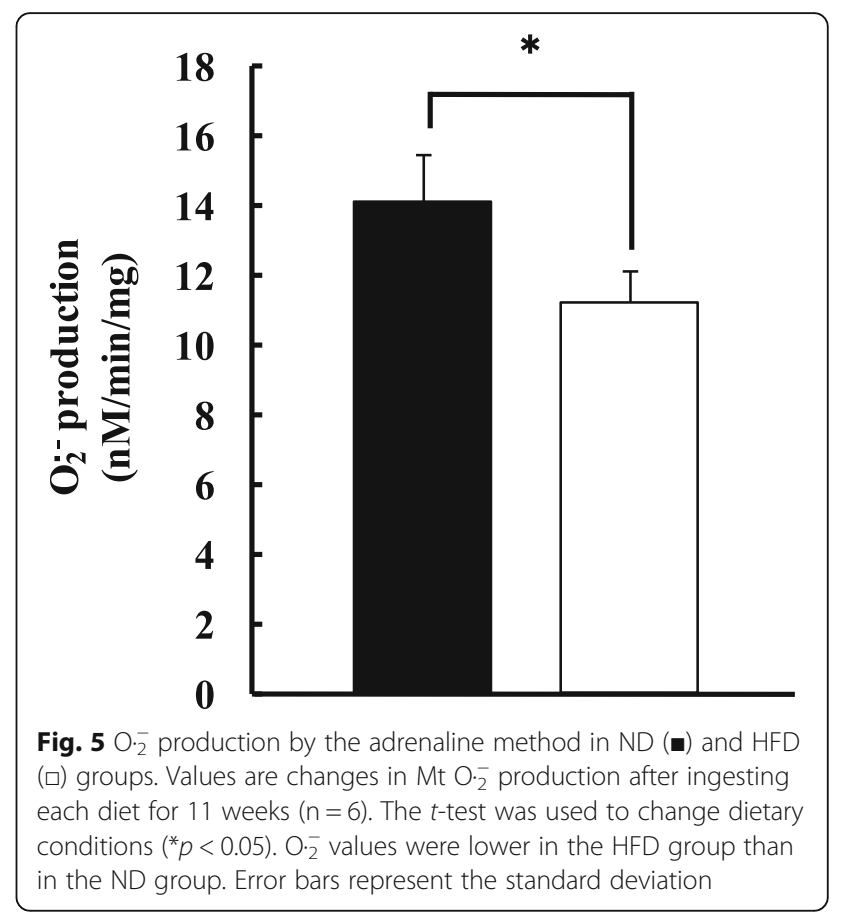

in HFD-fed rats than in ND-fed rats. No significant changes were observed in Mt membrane fluidity.

The period from 4 to 15 weeks old, during which rats were fed the HFD, accounts for suckling over puberty, which corresponds to adolescence [32]. Body weights (Fig. 3) and abdominal circumferences (Table 1) were markedly higher in the HFD group than in the ND group, and AI was higher in the HFD group (Table 2). Regarding the respiratory activity of liver Mt, RCR was 3 or higher, and the P/O ratio was 2.6 or higher [33], showing that it was possible to extract Mt in

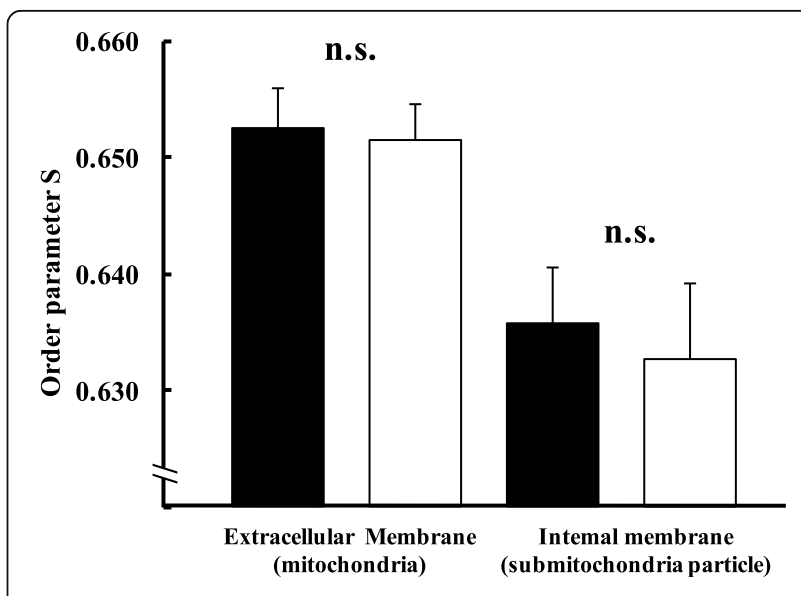

Fig. 6 Membrane fluidity of the cell membrane in ND ( $\mathbf{\square})$ and HFD ( $\square$ ) groups. Values are changes in Mt membrane fluidity after ingesting each diet for 11 weeks $(n=6)$. The $t$-test was used for changes in dietary conditions (no significance). The intake of a high fat diet for 11 weeks did not change Mt membrane fluidity. Error bars represent the standard deviation 
a favorable state under both conditions. The $\mathrm{P} / \mathrm{O}$ ratio, reflecting the amount of ATP synthesized by Mt, and substrate oxygen consumption were higher in the HFD group than in the ND group (Fig. 4). In rats fed a HFD, fatty acid metabolism was found to be promoted, energy metabolism increased [34], and citrate synthase activity was enhanced [35]. The amount of ATP synthesized increases in the liver in the compensatory phase [36], and the ingestion of a HFD increases the total amount of Mt [35]. RCR and the P/O ratio reflect the state and impermeability of the Mt inner membrane, substrate oxidization, and conjugation with oxidative phosphorylation. In HFD-fed rats, Mt functions, such as ATP synthesis and oxidative phosphorylation, were promoted to metabolize the fatty acids ingested.

$\mathrm{O}_{2}^{-}$production was measured in samples after removing the scavenging activity of Mn-SOD by ultrasonication using the adrenaline method. In the adrenaline method, adrenaline is oxidized by $\mathrm{O}_{2}^{-}$, and $\mathrm{O}_{2}^{-}$is quantitated based on one molecule of $\mathrm{O}_{2}^{-}$producing one molecule of adrenochrome. In $\mathrm{Mt}, 3-5 \%$ of oxygen becomes $\mathrm{O}_{2}^{-}$during ATP synthesis in the electron transport chain $[13,14]$ and is scavenged by the SOD, Mn-SOD [37]. $\mathrm{O}_{2}^{-}$production was lower in the HFD group than in the ND group (Fig. 5). In elderly rats fed a HFD, hydrogen peroxide production in the liver increased, RCR decreased [17], and hydrogen peroxide production in skeletal muscle increased [8]. In obese individuals, the amount of Mt decreased, thereby reducing Mt functions, such as oxygen consumption [38, 39]. We also previously demonstrated that oxidative stress may lead to cell damage in the skeletal muscle of dietinduced obese rats [40]. Regarding antioxidant capacity, the transcription level of antioxidative enzyme-related genes decreased in rats fed a HFD [41]. The increase in oxygen consumption and decrease in $\mathrm{O}_{2}^{-}$production accompanying the promotion of energy metabolism indicate a reduced antioxidant capacity, such as Mn-SOD expression [8]. In the present study, the ingestion of the HFD increased ATP synthesis and reduced $\mathrm{O}_{2}^{-}$production due to the promotion of fatty acid metabolism in the liver, suggesting that a reduction in antioxidant capacity occurred in the body. The genomic DNA of Mt is not protected by histones and is readily impaired by radicals. The respiratory chain, which plays a central role in energy metabolism, is located in close proximity, making it more susceptible to damage by ROS than in other cells. In a state of increased ROS production, such as exercise, exposure to ROS increases due to a reduction in the antioxidant capacity in the liver, which increases the possibility of cell damage by oxidative stress.

Moderate $\mathrm{O}_{2}^{-}$production is beneficial for up-regulating the infection-protective immune system and signal transmission for apoptosis in the body [9-11, 42]. A previous study reported that ROS production by Mt increases the phagocytic and migration abilities of macrophages [43].
Taking the function of ROS as a signaling molecule into account, the ingestion of a HFD from the juvenile period may impair liver Mt and have a negative influence due to reductions in ROS production in $\mathrm{Mt}$

In the present study, rats were fed lard with a high content of polyunsaturated fatty acids, which are cell membrane components. Many previous studies have employed aging model rats, dietary restrictions, and measurements of membrane fluidity in white blood cells [31, 44-46]. The spin label method used in the present study employed the labeling agent, 5-NS, and outer membrane fluidity was measured based on the nitroxide group binding to the alkyl chain of the phospholipid head on the external membrane surface. The relationship between $\mathrm{O}_{2}^{-}$generation and membrane fluidity in Mt has not yet been examined. Therefore, we attempted to investigate this relationship in the livers of rats fed a HFD. Lipids account for $25-30 \%$ of Mt membrane components, and polyunsaturated fatty acids and cholesterol are abundant [47]. We hypothesized that diet-induced obesity promotes structural changes in membrane phospholipids localized in the electron transport chain and increases $\mathrm{O}_{2}^{-}$leakage; however, no dietinduced change was noted in the fluidity of the Mt outer membrane or electron transport chain isolated by ultrasonication (Fig. 6). Although previous studies reported that membrane fluidity was altered with changes in the contents of cholesterol and phospholipids $[15,16]$, these findings were not consistent with the present study. The ingestion of a HFD has been shown to promote fatty acid oxidation due to changes in the fat composition of Mt and impaired oxidative phosphorylation [17]. Therefore, the promotion of lipid metabolism in the liver may have resulted in a decrease in lipid infiltration in the liver and had no influence on the Mt membrane.

Regarding the limitations of the present study, we isolated and analyzed the electron transport chain from Mt, but did not quantify $\mathrm{O}_{2}^{-}$in Mt after substrate-permeable cell processing. Future studies are needed in order to investigate this and examine the impact of the duration of a HFD on Mt and $\mathrm{O}_{2}^{-}$. Another aspect that warrants further study is the impact of an exercise protocol on antioxidant capacity and $\mathrm{O}_{2}^{-}$production.

\section{Conclusion}

The purpose of the present study was to evaluate the impact of HFD-induced obesity on $\mathrm{Mt} \mathrm{O}_{2}^{-}$production in the liver and assess changes in Mt membrane fluidity. We found that a HFD increased Mt respiratory activity and reduced $\mathrm{O}_{2}^{-}$production, but did not change membrane fluidity. Although $\mathrm{O}_{2}^{-}$damages cells as an oxidative stress, ROS and SOD are essential signaling molecules in the body. The present results suggest that the continuous ingestion of a HFD impairs Mt and induces disease development. 


\section{Abbreviations}

5-NS: 5-nitroxyl stearate; Al: augmentation index; FFA: free fatty acids; GA: glycoalbumin; HbA1c: glycated hemoglobin A1c; HDL: HDL cholesterol; HFD: high-fat diet; LDL: LDL cholesterol; Mt: mitochondrial; ND: normal diet; $\mathrm{O}_{2}^{-}$: superoxide anion; P/O ratio: ADP/oxygen ratio; RCR: respiratory control ratio; ROS: reactive oxygen species; SMP: submitochondrial particles; SOD: superoxide dismutase; T-ch: total cholesterol; TG: triglycerides

\section{Acknowledgements}

We would like to acknowledge Professor Fujii $\mathrm{H}$ of the Center of Medical Education, Sapporo Medical University who provided guidance throughout the course of this research. We would also like to thank everyone who cooperated.

\section{Funding}

Not applicable.

\section{Availability of data and materials}

The authors would like to share the data included in the manuscript.

\section{Authors' contributions}

TM and $\mathrm{KI}$ designed this research and wrote the initial draft of the manuscript. KN, TM, KR, and $Y T$ contributed to the analysis and interpretation of data, and assisted in the preparation of the manuscript. All other authors contributed to data collection and interpretation, and critically reviewed the manuscript. The final version of the manuscript was approved by all authors.

\section{Ethics approval}

Animal experiments were performed according to the guidelines on animal experiments of Rakuno Gakuen University (approval number: DH15A6, 2015).

\section{Consent for publication}

Not applicable.

\section{Competing interests}

The authors declare that they have no competing interests.

\section{Publisher's Note}

Springer Nature remains neutral with regard to jurisdictional claims in published maps and institutional affiliations.

\section{Author details}

'Graduate School of Dairy Sciences, Rakuno Gakuen University, 582, Midorimachi Bunkyodai, Ebetsu, Hokkaido 069-8501, Japan. ${ }^{2}$ Graduate School of Medicine, Sapporo Medical University, S1 W17, Chuo-ku, Sapporo, Hokkaido 060-8556, Japan. ${ }^{3}$ School of International Culture Relations, Tokai University, 5-1, Minaminosawa, Minami-ku, Sapporo, Hokkaido 005-8601, Japan. ${ }^{4}$ Asahikawa National Institute of Technology, 2-2-1-6, Syunkodai, Asahikawa, Hokkaido 071-8142, Japan. ${ }^{5}$ School of Health Sciences, Sapporo Medical University, S1 W17, Chuo-ku, Sapporo, Hokkaido 060-8556, Japan. ${ }^{6}$ Department of Education, Hokkaido University of Education Sapporo, 3- 5, Ainosato Kita-ku, Sapporo, Hokkaido 002-8502, Japan.

\section{Received: 13 July 2017 Accepted: 5 March 2018}

\section{Published online: 14 March 2018}

\section{References}

1. Oono H, Atomi J. Fushiki H.Active oxygen and exercise. Japan: Kyorin Syoin. 1998;109-117:24-5

2. Yamada N. Concept of metabolic syndrome and clinical diagnostic criteria. J Japanese College Angiology. 2006;46:417-22.

3. Wannamethee SG, Tchernova J, Whincup P, Lowe GD, Kelly A, Rumley A Wallace AM, Sattar N. Plasma leptin: associations with metabolic inflammatory and haemostatic risk factors for cardiovascular disease. Atherosclerosis. 2007:19(2):418-26.

4. Huang CJ, McAllister MJ, Slusher AL, Webb HE, Mock JT, Acevedo EO. Obesity-related oxidative stress: the impact of physical activity and diet manipulation. Sports Med Open. 2015;1(1):32.

5. Furukawa S, Fujita T, Shimabukuro M, Iwaki M, Yamada $Y$, Nakajima $Y$, Nakayama O, Makishima M, Matsuda M, Shimomura I. Increased oxidative stress in obesity and its impact on metabolic syndrome. J Clin Invest. 2004 114:1752-61.
6. Keaney JF Jr, Larson MG, Vasan RS, Wilson PW, Lipinska I, Corey D, Massaro JM, Sutherland P, Vita JA, Benjamin EJ. Obesity and systemic oxidative stress: clinical correlates of oxidative stress in the Framingham study. Arterioscler Thromb Vasc Biol 2003; 23(3): 434-439.

7. Demori I, Voci A, Fugassa E, Burland B. Combined effects of high-fat diet and ethanol induce oxidative stress in rat liver. Alcohol. 2006:40:185-91.

8. Gómez-Pérez Y, Amengual-Cladera E, Català-Niell A, Thomàs-Moyà E, Gianotti M, Proenza AM, Lladó I. Gender dimorphism in high-fat-dietinduced insulin resistance in skeletal muscle of aged rats. Cell Physiol Biochem. 2008;22:539-48.

9. Montezano AC, Touyz RM. Reactive oxygen species and endothelial function-role of nitric oxide synthase uncoupling and Nox family nicotinamide adenine dinucleotide phosphate oxidases. Basic Clin Pharmacol Toxicol. 2012;110(1):87-94

10. Kunwar A, Priyadarsini Kl. Free radicals, oxidative stress and importance of antioxidants in human health. J Med Allied Sci. 2011;1(2):53-60.

11. Vider J, Laaksonen DE, Kilk A, Atalay M, Lehtmaa J, Zilmer M, Sen CK Physical exercise induces activation of NF-kappaB in human peripheral blood lymphocytes. Antioxid Redox Signal. 2001:3(6):1131-7.

12. Boveris $A$, Chance $B$. The mitochondrial generation of hydrogen peroxide general properties and effect of hyperbaric oxygen. Biochem J. 1973;134:707-16.

13. Boveris A, Noir BA, Perez V, Stoppani AO. The function of liver mitochondria after steroid administration. Rev Soc Argent Biol. 1972;48-49:73-83.

14. Grisham MB, Granger DN. Metabolic sources of reactive oxygen metabolites during oxidant stress and ischemia with reperfusion. Clin Chest Med. 1989; 10:71-81.

15. Ciapaite J, Broek NMVD, Brinke HT, Nicolay K, Jeneson JA, Houten SM, Prompers $J$ J. Differential effects of short-and long-term high-fat diet feeding on hepatic fatty acid metabolism in rats. Biochim Biophys Acta. 2011;1811:441-51.

16. Tanaka T, Ogura R, Hidaka T, Sugiyama M. Changes of electron spin resonance membrane fluidity in hexadecane-induced hyperproliferative epidermis. J Invest Dermatol. 1989;93:682-6.

17. Vial G, Dubouchaud H, Couturier K, Rousselle CC, Taleux N, Athias A, Galinie A, Casteilla L, Leverve XM. Effects of a high-fat diet on energy metabolism and ROS production in rat liver. J Hepatol. 2011;54:348-56.

18. Murgo JP, Westerhof N, Giolma JP, John P, Giolma PD, CPT MSC, Stephen A Altobelli MS, ILT SIGC. Aortic input impedance in normal man:relationship to pressure wave forms. Circulation. 1980;62:105-16.

19. Nichols WW, O'Rourke MF, Avolio AP, Yaginuma T, Joseph PM, Carl JP, Richard C. Effects of age on ventricular-vascular coupling. Am J Cardiol. 1985;55:1179-84.

20. Takazawa K. A clinical study of the second component of left ventricular systolic pressure. J Tokyo Med Coll. 1987;45(2):256-70.

21. Shimonishi $Y$, Nagai $K$, Nagaya $S$, Honda T. Selection of biochemical experiments. Japan: Chemistry dictionary; 1996. p. 55-69.

22. Bradford M. A rapid and sensitive method for the quantitation of microgram quantities of protein utilizing the principle of protein-dye binding. Anal Biochem. 1976;72:248-54

23. Murofushi $H$, Murofushi K. Experimental method of basic biochemistry. Ohm Inc for Japanese. 1986:157-61.

24. Hagihara B. Techniques for the application of polarography to mitochondrial respiration. Biochim Biophys Acta. 1961;46:134-42.

25. Tanemura A. Study of mitochondria by electron spin resonance absorption - with special emphasis on respiratory condition. Kanazawa University Repository for Academic Resour. 1971:80(1):66-75.

26. Watabe T. Examination of gingival mitochondrial adjustment method using breath control rate as index and its effect on respiratory activity of leukotoxin. Fukuoka Dental College university magazine. 1999;26(4):219-30.

27. Chance B, Williams GR. The respiratory chain and oxidative phosphorylation. Advanc Enzymol. 1956;17:65-134

28. Estabrook RW. Mitochondrial respiratory control and polarographic measurement of ADP/O ratio. Method Enzymol. 1967;10:41-7.

29. Takeshige K, Minakami S. NADH-and NADPH-dependent formation of superoxide anions by bovine heart submitochondrial particles and NADHubiquinone reductase preparation. Biochem J. 1979;180:129-35.

30. Turrens JF, Boveris A. Generation of superoxide anion by the NADH dehydrogenase Ob bovine heart mitochondria. Biochem J. 1980;191:421-7.

31. Gabbita SP, Butterfield DA, Hensley K, Shaw W, Carney JM. Aging and caloric restriction affect mitochondrial respiration and lipid membrane status:an electron paramagnetic resonance investigation. Free Radical Biology Med. 1997;23:191-201. 
32. Satou T. Basics of animal experiments. Japan: Nishimura Shoten; 1986. p. 38-9.

33. Ustumi K, Inoue M. New mitochondriaology. Japan: Kyoritsu Publishing; 2001. p. 122-6.

34. Flamment M, Rieusset J, Vidal H, Simard G, Malthiery Y, Fromenty B, Ducluzeau PH. Regulation of hepatic mitochondrial metabolism in response to a high fat diet: a longitudinal study in rats. J Physiol Biochem. 2012;68: 335-44

35. Higashida K, Mikami E, Sonou T, Higuchi M, Terada S. Dietary fatty acids influence mitochondrial enzyme activities and PGC-1a protein content in rat skeletal muscle. Japan Society of Exercise and Sports. Physiology. 2008; 15:45-51.

36. Ozawa K. The limits of liver surgery and perspective on its future from the viewpoint of metabolic function. Japan Society of Digestive Surgery. Journal. 1980;13(8):910-9.

37. Taniguchi N. Clinical significances of superoxide dismutases:changes in aging, diabetes, ischemia, and cancer. Adv Clin Chem. 1992; 29:1-59.

38. Petersen KF, Dufour S, Befroy D, Garcia R, Shulman Gl. Impaired mitochondrial activity in the insulin-resistant offspring of patients with type 2 diabetes. N Engl Med. 2004;350(7):664-71.

39. Ritov VB, Menshikova EV, He J, Ferrell RE, Goodpaster BH, Kelley DE. Deficiency of subsarcolemmal mitochondria in obesity and type 2 diabetes. Diabetes. 2005:54:8-14.

40. Konari N, Tsukamoto M, Togo M, Kimoto R, Uchida E, Takeda H, Kambayashi I. Effect of high-fat feeding on scavenging activity of reactive oxygen species in rat skeletal muscle. Journal of Hokkaido physical. Education Research. 2012:47:35-41.

41. Sreekumar R, Unnikrishnan J. Fu a, Nygren J, short KR, Schimke J, Barazzoni R, Sreekumaran Nair K. Impact of high-fat diet and antioxidant supplement on mitochondrial functions and gene transcripts in rat muscle. Am J Physiol Endocrinol Metab. 2002;282:E1055-61.

42. Radak Z, Chung HY, Koltai E, Taylor AW, Goto S. Exercise, oxidative stress and hormesis. Ageing research review. 2008;7:34-42.

43. Miyake T, Shirakawa H, Nakagawa T, Kaneko S. Activation of mitochondrial transient receptor potential vanilloid 1 channel contributes to microglial migration. Glia. 2015;63(10):1870-82.

44. Haak RA, Ingrahan LM, Baehner RL, Boxer LA. Membrane fluidity in human and mouse Chediak-Higashi leukocytes. J Clin Invest. 1979;64:138-44.

45. Ingraham LM, Burns CP, Boxer LA, Baehner RL, Haak RA. Fluidity properties and lipid composition of erythrocyte membranes in Chediak- Higashi syndrome. J Cell Biol. 1981;98(3):510-6.

46. Gabbita SP, Subramaniam R, Allouch F, Carney JM, Butterfield DA. Effects of mitochondrial respiratory stimulation on membrane lipids and proteins:an electron paramagnetic resonance investigation. Free Radical biology Med. 1998:1372:163-73.

47. Hara Y, Oota E. Standard biochemistry. Japan: Bunkodo; 2004. p. 124-40.

\section{Submit your next manuscript to BioMed Central and we will help you at every step:}

- We accept pre-submission inquiries

- Our selector tool helps you to find the most relevant journal

- We provide round the clock customer support

- Convenient online submission

- Thorough peer review

- Inclusion in PubMed and all major indexing services

- Maximum visibility for your research

Submit your manuscript at www.biomedcentral.com/submit

) Biomed Central 